\title{
A Tentative Study on Ward Monitoring System based on Zigbee Technology
}

\author{
Jifeng Liang \\ Xi'an Fanyi University, Xi'an Shaanxi 710105 China \\ 3480418792@qq.com
}

Keywords: Zigbee technology; CC2530 chip; Wireless sensor network; Ward monitoring

\begin{abstract}
ZigBee technology is a two-way wireless communication technology. In recent years, wireless sensor network technology based on Zigbee technology has been widely used in many fields, such as environment monitoring, medical care etc. This paper mainly introduces the Zigbee technology, and the Zigbee wireless sensor network, designed to monitor the temperature and humidity of medical environment and the heart rate. This design principally uses CC 2530 chip to connect the sensor nodes and the central node; the temperature and humidity sensor and heart rate sensor to form the terminals of the wireless sensor network; simulation experiment and modularization to realize the overall system function. At the same time, it reduces the costs and improves the network security and reliability.
\end{abstract}

\section{Introduction to Zigbee}

With the improvement of science and technology, people have new understanding and high requirement to communication technology. Wireless communication technology is one of its kind. The widely-used short distance wireless communication technology includes WI-FI technology, Zigbee technology, Bluetooth technology. Bluetooth technology started earlier with its sophiscated technology but limited transmission distance and network capacity, WI-FI technology fixes some shortcomings of Bluetooth technology, but also has high power consumption and high costs; Zigbee technology advances with the advantages of the former two technologies, avoiding deficiency in the aspect of cost, power and network capacity. Based on the IEEE802.15.4 wireless standard, Zigbee is mainly used in short distant, low-rate electronic devices. Its data transmission type is periodic data, such as sensor data. Zigbee technology functions well between household appliances and small electronic equipment. ZigBee technology is now widely used in commerce, agriculture, manufacturing industry and medical industry.

\section{Overview of Medical Ward Monitoring}

The widely-used ZigBee wireless sensor network technology has the advantages of wide coverage of communication, huge communication nodes, and huge amount of information, high communication speed and high security. With the help of Zigbee's mature but low-cost sensor module to build a small wireless sensor network, monitoring of temperature and humidity in the medical wards, the detecting of the hear rate can be done; so that every patient data can be sent directly through the automatic wireless sensor network to the information management system. It greatly saves time and energy of the nurses; more importantly, it provides the solid and in-time data for the doctors to take immediate measures to treat patients.

\section{Medical Ward Monitoring System}

System Structure Diagram. The system is mainly composed of Zigbee transmission core CC2530 module, LCD display module, serial port module and sensor module, as shown in Fig. 1 for the system hardware diagram. 


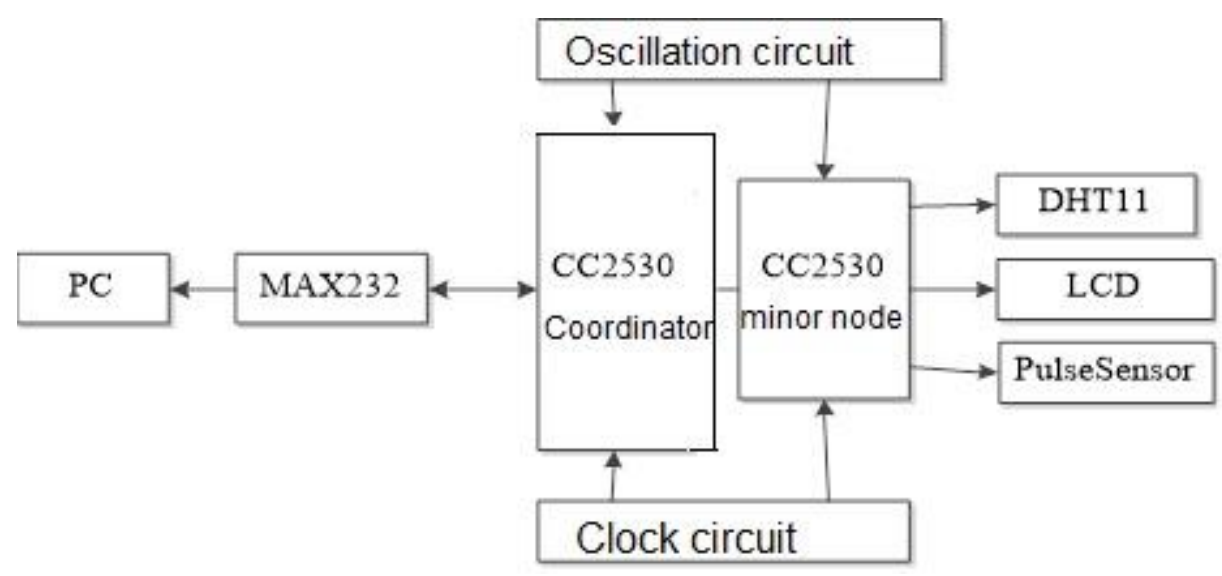

Figure 1. System hardware diagram

CC2530 Module Design. The use of CC2530 chip in the design is a proper option for Zigbee application with a variety of memory access bus, and accessible wireless download to facilitate system maintenance and user upgrades. It is equipped with a highly precise built-in temperature sensor, advanced RF transceiver with 8051 chip, powerful and programmable Flash. Its powerful features reveal on $8 \mathrm{~KB}$ memory and the compatibility with the IEEE802.15.4 protocol. The function of CC2530 module is to send the sensed data to the control terminal. It can build powerful network nodes with very low cost in material. These chips have advantage in USB download, and can be connected to a variety of development environment and received by $8051 \mathrm{MCU}$ with superb performance and low power consumption. CC2530 module has excellent performance and strong anti-interference ability.

CC2530 circuit is shown in Fig. 2

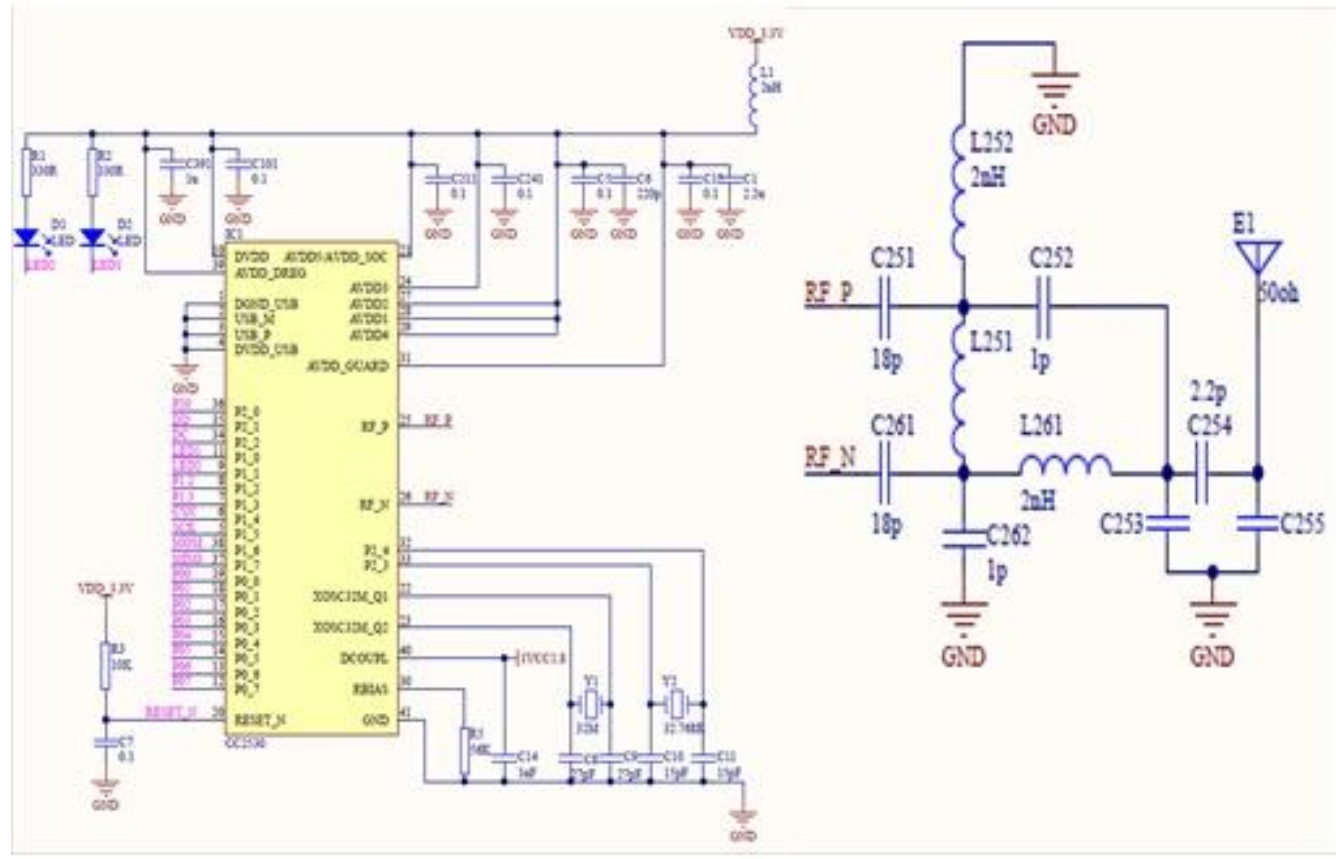

Figure 2. CC2530 circuit

\section{Sensor Module Design}

(1) temperature and humidity sensor design

CC2530 chip and DHT11 chip are used in temperature and humidity sensor in the system. DHT11 chip, a digital temperature and humidity sensor chip, is widely used in heating and air conditioning, electronics, automatic control and other fields. This highly compressed chip combines temperature and humidity testing, signal transform, heaters and other functions in a single chip, 
providing two-way digital serial interface of IO SCK and DATA. It is of simple operation and able to check CRC transmission. It is very secure in transmission and capable of interference prevention in the measurement by using CMOS technology.

(2) pulse sensor design

The Pulse Sensor, a photoelectric reflection pulse rate measurement simulation device, can be worn on the human fingers, earlobes etc., can convert the acquired analog signals to digital signals through CC2530 chip and then calculate the value of heart rate.

Serial Port Module Design. The main node CC2530 converts the TTL level to RS-232 level through MAX232 to have serial communication with PC. This design uses MAX232 as the RS-232 interface chip, as shown in Fig. 3.

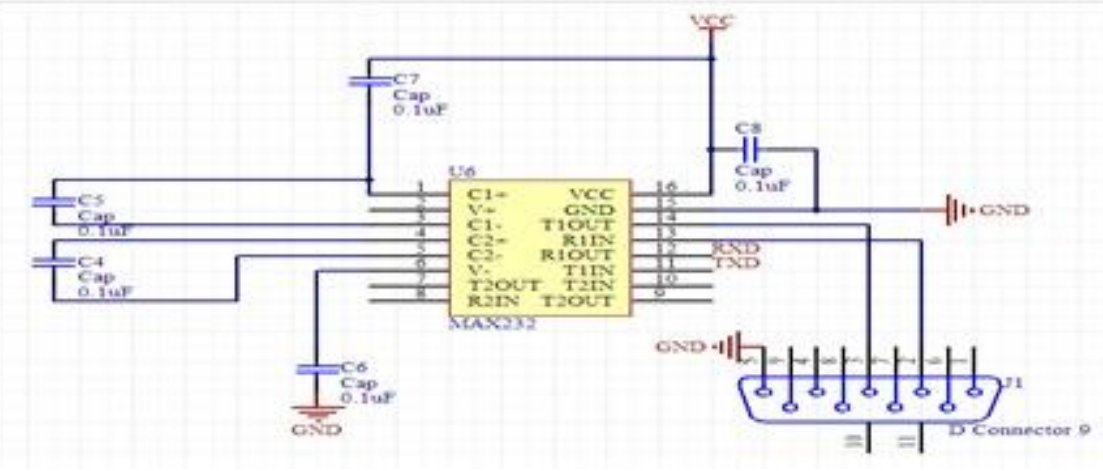

Figure 3. MAX232 interface circuit

Display Circuit. LCD12864 (liquid crystal display) is widely called 12864, because it can display 128 columns and 64 rows. It can simultaneously display LCD display with 128 characters; backlight circuit with separate power supply can display well at night. Gray in the liquid crystal can also transform and display well. The design adopts LCD12864 to display data. Fig. 3.4 is for LCD display circuit

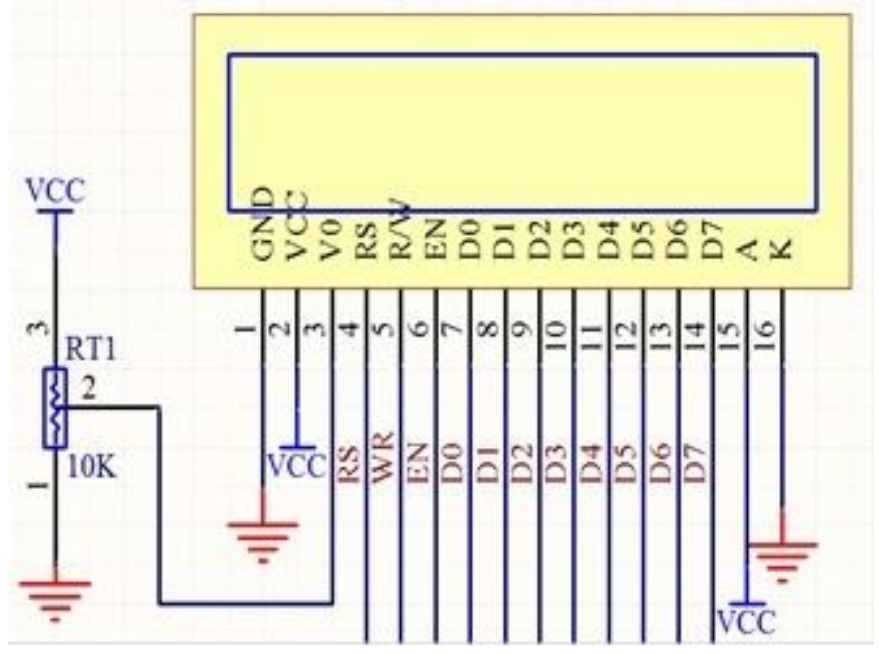

Figure 4. LCD display circuit

\section{System Debugging}

Through the full preparation, the design is complete on the basis of the above theoretical knowledge. The first step is to complete theoretical structure and explore and think hard while encountering problems. From the initial plan to the forming principle, optimization of the circuit design and the check of the system stability guarantee the system stable work. The final step is to weld multifunctional circuit board to produce circuit system, following the "low-to-high" principle. 
As shown in Fig. 5, the left device is terminal node, while the right one is the coordinator in the system. While the power is on, if the terminal nodes are successfully connected, the LED3 on the terminal knot turns off, otherwise LED3 blink to wait to connect to the network.

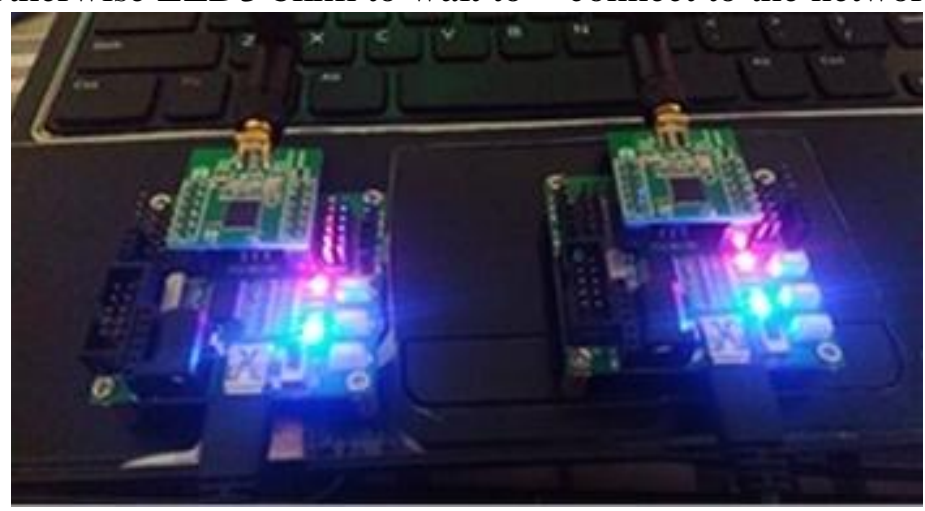

Figure 5. knot operation effect

\section{Conclusion}

The combination of the traditional temperature and humidity detection with the fast and accurate Zigbee wireless sensor network technology give full play to their advantage on technology to achieve the best effect of the design.

The use of the CC2530 chip as the core control unit is compatible with the reasonable arrangement of each module in circuit; the tests of the indoor temperature and humidity, together with the pulse sensor, guarantees the design reach its initial goal.

\section{Acknowledgements}

Project Source: Xi'an Fanyi University

Project Number: 16B03

\section{References}

[1] Yajun Guo, Liang Wang, and. Internet of things foundation. Beijing: Tsinghua University press, 2013(in Chinese)

[2] Yufang Du. Wireless temperature and humidity collector. Information technology based on nRF905 and DHT11. 2012 (08). (in Chinese)

[3] Ankun He, Liang Zhang, Jin Xue. Design and implementation of intelligent home system based on ZigBee technology. Microcomputer information. 2012 (09). (in Chinese)

[4] Jian Yu, Hong Liu. LED lighting control system based on ZigBee wireless sensor network. Mechatronics Engineering. 2012 (11). (in Chinese)

[5] Fei Li. Intelligent home system design based on Internet of things technology. Electronic production.2014 (16): 36-37. (in Chinese)

[6] Ya Tian. Design and implementation of wireless sensor network system based on. Zigbee Tongii University.2007. (in Chinese)

[7] Xue Xue, Qin Gang. ZigBee stack research and simulation. Xi'an: Xi'an University of Technology Master's degree thesis, 2010 (in Chinese),.IEEE802.15.4

[8] Li Ma. Realization. Wuhan design and remote data monitoring wireless sensor network based on ZigBee: Master's degree thesis of Wuhan University of Technology.2010. (in Chinese) 
[9] Weiwei Xing, Ruilin Bai, Wei Meng. Application of ZigBee wireless gateway in MODBUS communication. Computer engineering and applications. 2011 (29). (in Chinese)

[10] Xiaoyu Tong, Li Jun Fang, Yunyong Zhang. Development of intelligent home networking. Mobile communication. 2010 (09). (in Chinese) 